en virtud de las cuales nos explicamos cl mundo, nos relacionamos entre nosotros y construimos nuestra identidad.

Creo que es significativo que este programa se realice en paralelo con otros intentos de reubicación de la herencia normativa de la modernidad desde la revisión de algunos de sus supuestos epistémicos, tal como la que está teniendo lugar en múltiples lugares de la filosofia contemporánea. Que las reubicaciones americanas cuenten con los acentos peculiares de sus propias tradi- ciones intelectuales es logico y comprensible. Pero quizá esos acentos apunten a algo más que a un rasgo idiosincrático - que fue como, con torpeza, reaccionaron sectores de la filosofía europea ante el pragmatismo de comienzos de siglo- y nos indiquen que percibir la herencia ética de la modernidad puede implicar adoptar lenguajes mcnos trascendentales, aunque no menos racionales, de lo que nos tienen acostumbrados las tradiciones académicas de acá.

\title{
NOTAS
}

1. Ideals and Illusions. On Reconstriction and Deconstruction in Contemporary Critical Theory, Cambridge, MA, The MTT Press, 1991. (Existe versjôn castellana de Angel Rivero, Ideales e ilusiones, Madrid, Tecnos, 1992.) Citaremos, en el texto, la página del original ingles.

2. La Teonia Critica de Jurgen Hobemas, trad, de M. Jiménez Redondo, Madrid, Taurus, 1987 (original de 1978).

3. McCarthy ha sistematizado la visión global de su propuesta - que, según señala en una nota a pie de página, desarrollará en un próximo libro- en la sintesis ofrecida en el articulo de igual título del libro que comentamos, uldeales e nusiones", La Ealsa de la Medusa, 21 (1992).

4. Una versión anterior de este capitulo aparecio, bajo el título aIronía privada y decencia pública: el nuevo pragmatismo de Richard Rorty", $L a$ Balsa de la Medusa, 8 (1988).

5. Una versión anterior de este capitulo aparecio bajo el título wTeoria Crítica en Estados Unidos: Foucault y la Escuela de Frankfurt", Isegorha, 1 (1990).

6. Una versión anterior del mismo apareció en castellano, con idéntico título, la Balsa de la Medusa, 12 (1989).

\section{Fundamento y Ética}

\author{
TERESA LÓPEZ DE LA VIEJA DE LA TORRE \\ Universidad de Salamanca
}

\section{El fundamento}

Nos hallamos del otro lado, en el forro de las cosas, en la penumbra hilvanada con la embrolladora fosforescencia. ¡Qué circulación, qué dinamismo, qué multitud! ¡Qué impaciente magma de pueblos y generaciones. Biblias e Iliadas mil veces repetidas! ¡Qué emigraciones y barullos, marañas y rumores de la historia! El camino se detie- ne aquí. Nos hallamos en el mismo fondo, en los sombrios fundamentos... [B. Schulz: Sanatorio bajo la clepsidra, Barcelona, Montesinos, 1986, p. 79].

El uso del término «fundamento» colabora para que nos representemos las disciplinas a las cuales se aplica como estructura organizada. El fundamento confiere estabilidad a los elementos, 
ción y fundamentación completas están excluidas cuando las actividades tienen la última palabra. La colectividad o el individuo serán los últimos o primeros responsables de una toma de decisiones. Por ejemplo, ninguna explicación práctica retrospectiva puede asegurarnos que un acontecimiento desgraciado y producido por agentes humanos fue necesario $y$, por lo tanto, un mal necesario a asumir, a ser posible con la colaboración de virtudes morales del tipo resignado. Las tareas de fundamentación permanecerán afortunadamente inconclusas, afortunadamente, pues, una única solución cegaría la vía de acceso a la reflexión, la crítica y, en otro nivel, a la Ética, la Moral, la Moralitüt e incluso la Sittichkeit. De lo contrario. una incitación a dar con algo definitivo vendría a dar cobijo teórico a una velada o menos velada apología de soluciones finales, en la línea de un empleo contundente de medios aún más contundentes; la fuerza vendria a ocupar el lugar de todas las razones y noma de normas. Normas bien fundadas sí, pero por y para los implicados en un proceso de decisión, en un marco determinado; reglas abiertas, en fin, para rehacer, reconstruir o construir la racionalidad, "Suficiente» para las necesidades y posibilidades reales.

La Ética puede dedicar importantes esfuerzos a los "fundamentos", si no se deja llevar por la sugestión de hallar en ellos el absoluto que no encuentra ni puede encontrar para resolver sus incógnitas. Un fundamento suficiente, determinado, limitado será una forma de decir qué razones se consideran más verosímiles, más adecuadas para argumentar en contra de actos cuya motivación descansa tan sólo en la fuerza o poder abusivo, particular o general. Por consiguiente, la Filosofia moral encuentra todavía su piedra de toque en el problema de los fundamentos, si bien en un sentido distinto a como pudo entenderse en otros momentos, o por parte de ciertos autores con fuertes intereses ontológicos o teológicos. Además la tarea de fundamentación está limitada por un marco nomativo y por los problernas de aplicabilidad; los límites por aniba y por abajo no permiten que el filósofo moral resuelva en solitario sus dificultades, de tantas implicaciones morales y prácticas. Considérese que se trataría de una Ética sin Metafísica, una Ética de imperativos hipotéticos, no categóricos, Ética de razones y justificaciones en lugar de causas, Ética de procedimientos verosímiles y no de certezas absolutas. Por consiguiente, requerirá de una fundamcntación en el sentido de justificaciones y argumentos, en tanto se mantenga unida a los avatares de la racionalidad. Y como este segundo concepto, la uracionalidad", ha sido sometido a intensísimo debate, el «fundamento" ha de pasar por una profunda revisión. 
como si éstos formasen parte de una organización jerárquica bien formada. Gracias a los elementos básicos o fundamentales, la disciplina en cuestión cumplirá eficazmente tareas de referencia o de análisis. Esta hipótesis tiende a generalizarse incluso cuando la correcta disposición para las funciones de análisis no comporta una referencia adecuada a objetos. En la mayoría de los casos, los «fundamentos» aluden a una estructura básica, sobre la cual se organiza un sistema conceptual, apto para diversos cometidos; resulta esencial atribuirle un fundamento que garantice la consistencia de lo construido al efecto. No siempre o en todas las disciplinas se puede contar con un sistema de tales características, como sucede en buena parte de las Ciencias Humanas y en la Filosofía. La inercia a suponerles orden geométrico crea un sinfín de dificultades que, a la postre, redundan en perjuicio de las mismas disciplinas por haberse sometido éstas a los dictados de un modelo inadecuado. En tales casos será preciso considerar si el empleo del término, si el "fundamento" no tiene un uso más bien analógico o incluso de carácter abiertamente metafórico. Ello no invalidaría la fundamentación que allí se hubiere realizado, no, porque la revisión teórica tiene un límite, el cual coincide con las fases y modos de la formación por la que pasaron las mismas disciplinas durante periodos más o menos dilatados, según los avatares de cada una de ellas. Este enfoque sí obligaría a indagar sobre el tipo de reglas seguidas para formarlas $\mathrm{y}$ sobre su funcionamiento; en suma, invita a considerar la racionalidad en virtud de la cual se construyeron. El objetivo de este trabajo es plantear la hipótesis de analogia o el fundamento como la metáfora de un punto arquimédico. Punto arquimédico poco deseable por otra parte, si consideramos el relativo grado de confusión e incluso de irracionalidad que podría introducir. Ha de considerarse esta segunda posibilidad, la del uso metafórico o alternativo, por cuanto que un uso inequívoco del mismo no es posible en términos absolutos para las disciplinas prácticas.

En Ética el "fundamento" carece de un uso específico, es decir, de un uso que indique sin ambigüedades cuáles son las bases de una «ciencia de las costumbres». El hecho de que el término se haya generalizado en el transcurso del tiempo no asegura un resultado indiscutible al respecto, sino que demuestra lo constante de una preocupación. Pudiera ser incluso más relevante la naturaleza y significado de tal preocupación que las distintas acepciones que el término ha ido recibiendo; con toda probabilidad la intención que subyace bajo las operaciones de fundamentar o el objetivo con ello buscado resultará mucho más significativo que su conclusión efectiva. La búsqueda insistente de un Faktum demuestra precisamente su falta de evidencia, de modo que se trataría más bien de un factum o de un faciendum, de una construcción. Hemos de ver en esto el reiterado intento de los filósofos por responder de modo conveniente a los desafios que, por oleadas y ciclos bastante regulares, les arrojan las ciencias más ortodoxas. Por tanto, el "fundamento" corresponde a un uso que no podemos considerar impropio para la praktiké epistérne, pero desde luego no el más adecuado. Tal desajuste o inadecuación se pone de manifiesto cuando se pretende que el trabajo fundamentador aporte evidencias alli donde no pueden darse $y$, por paradoja, acaba por reforzar una huida hacia seguridades u oscuros garantes, cuya procedencia no es precisamente la razón sino la mayor confusión y, por qué no decirlo, la apuesta más peligrosa para el pensar. Su presencia en la terminología 
común revela la poderosa sugestión ejercida sobre las disciplinas filosóficas por la confrontación con lo exterior, sea éste el universo en su conjunto o bien la concurrencia con otros saberes. La analogía del fundamento cumple sin embargo un vacío importante de la Filosofía moral. Un crecimiento ordenado de los conceptos y los argumentos prácticos cumpliría en un principio a satisfacción los requisitos del saber moderno, sobre todo cuando se muestra atraído por el ideal de la geometría. Descartes dio la entrada para un punto de apoyo arquimédico, para los axiomas de una correcta deducción, pero es difícil, por no decir imposible, organizar del mismo modo los saberes prácticos. Resulta obvio señalar que éstos admiten con dificultad, por sus objetivos y estructura una organización que corresponde al saber por causas y necesario, como se decía en el lenguaje clásico. Entonces puede resultar muy dificil el identificar correctamente el fundamento que les conviene, pero, por otro lado, la atención que suele prestarse a cuestiones consideradas fundamentales no podrá destinarse a otras menos básicas, aunque más sustantivas, si no se satisface alguna condición. Por ejemplo, la rotura de un vínculo que une saber práctico con la certeza sobrevenida por procedimientos analíticos. En todo caso no convendria perder de vista los molivos por los cuales la Filosofía moral insiste en la búsqueda, un punto ansiosa, de soportes resistentes sobre los cuales avanzar. Ese fuerte atractivo que parece ejercer la certidumbre no sólo agrava la presión teórica sobre el avance del saber práctico, sino que contribuye de modo determinante a introducir problemas que sólo agrandan las dimensiones de lo que pudiera no ir más lejos que una metáfora, una analogía. Y los márgenes de incertidumbre y azar en que se mueve ese saber práctico son ya lo sufi- cientemente amplios, de modo que una actitud de prudencia aconseja no ensancharlos sin motivo fuerte, no proseguir más allá de ciertos límites que son los de lo razonable.

Pocas tareas hay para la Filosofía moral tan inciertas como esa búsqueda de algo fundante, pero una abierta sugerencia a considerarla como un signo de otras pesquisas podría encontrar resistencia. Quizás la interpretación literal de los términos no sea un método adecuado, máxime cuando los intérpretes han llegado a ser multitud, y las tradiciones, menos abundantes de lo que pudiera pensarse. Parece lógico suponer que los hipotéticos resultados ofrecidos por una renuncia a la verdad, como único término aceptable y capaz de legitimar un razonamiento práctico, removería buena cantidad de supuestos o convicciones epistemológicas que nutren a los filósofos morales. Dejar en un segundo plano a certezas y fundamentos sólidos significa invertir esfuerzos en cuestiones que atañen a las formas, estructura, metodología, etc., y obliga además a un ajuste de cuentas con las corrientes que llevan décadas, estas últimas dos décadas, dinamizando el clásico debate entre Ciencias Humanas y Ciencias de la Naturaleza; corrientes tales como el positivismo más o menos clásico, las hermenéuticas de vario signo, con los postempíricos, los postestructuralistas y demás tendencias. La tarea quizás se presente en términos y magnitudes que desbordan la aspiración propia del filósofo moral, aun cuando el eco de esos debates y avances epistemológicos haya sensibilizado de forma tan determinante sus propios debates. Por tanto, la complejidad no haría sino aumentar si se procediese a la sustitución del fundamento por otro término, más ajustado a las ocupaciones y circunstancias intelectuales en que hoy se mueve la Ética. Claro es que se trata 
de un riesgo a asumir o, por el contrario, a eludir mediante alguna simplificación, cuyas ventajas también resultan dudosas. Considérese además que la ruptura con la creencia de que fundamentar es algo así como contribuir de forma inequívoca al progreso de las disciplinas prácticas implica ser conscientes de los distintos condicionantes que pesan sobre la mentalidad de una época, y no siempre se está en situación o hay voluntad de hacer un examen en profundidad en tal sentido. Implica en fin hacer balance con las necesidades efectivas del propio momento y circunstancia, averiguar por qué produce tal desasosiego la idea de estar pensando $\sin$ bases firmes, $\sin$ soportes indudables, por qué de tanta resistencia a la duda, elemento que debería ser ya habitual para la filosofía y no mero episodio del ingenio moderno. ¿Por qué motivos no se desea abandonar la fundamentación? O qué se espera en realidad de un elemento que sólo muy parcialmente podría suplir las carencias y negaciones que se han atribuido a la disciplina en su conjunto. Por azares varios, una respuesta en términos de "sí» o «no" resulta inviable, de manera que será oportuno entrar en el terreno de los matices.

Veamos algunos motivos para sostener ese uso matizado del "fundamento". La ausencia de cielo prolector contribuye a que no se desvíen sistemáticamente las energías intelectuales hacia la $\mathrm{Me}$ taética, en ventaja de la construcción teórica de Ética y Moral. Es más, el antagonismo entre planteamientos rigurosamente fundados y otros meramente justificados - lo cual no es poco- supone restar argumentos para la habitual oposición entre cognitivismo y no cognitivismo, en la medida en que insiste en otros distintos, cuales son los planteamientos plenamente constructivistas; éstos no sostienen pretensiones fuertes, ni cpistemológicas ni ontológicas. Así pues el empleo analógico del "fundamentos debe contribuir a mantener a la Filosofía moral en los márgenes que puede reivindicar, por tradición y por el tipo de posiciones que suele mantener. Habiendo reducido sus expectativas con respecto al comienzo y final que le corresponden, la reflexión empieza a valorar el proceso mismo. Lo sustantivo no reside entonces en el punto de partida bien asegurado o en el término final, sino en lo sucedido durante la formación de un saber determinado, de una explicación ad hoc. El resumen que podemos hacer del viaje de Ulises, como el episodio o conjunto de episodios de alguien que sale y vuelve a un lugar llamado Itaca, nada dice de las transformaciones y experiencias ocurridas durante el trayecto, que era lo esencial a efectos de la comprensión y explicación del caso. La fundamentación no es la noticia cierta con la cual echar las bases de un recorrido intelectual, sino la forma de identificar cómo alguien o un grupo se representa la moralidad. Los fundamentos indican cómo ese alguien, ese grupo o esa cultura organizan la expresión y la recepción de contenidos morales, ya sea el bien, la justicia, la felicidad u otros semejantes; para ello no se requiere evidentemente la copia precisa de una deducción rigurosa. $\mathrm{El}$ "fundamento" es una forma de representarse algo, más que un axioma; en lugar de apurar su significado literal, convendría entonces averiguar qué funciones desempeña en los distintos discursos de la Ética. Un fundamento no es como la adivinanza de la esfinge, sin la cual no se pasa adelante, sino la forma o incluso el símbolo para designar los contenidos o los problemas más significativos del saber práctico. Los fundamentos de la Ética son tan distintos como las etapas por las que ésta ha pasado, tanto como lo son las épocas y las lenguas en que se ha dicho algo de su 
"fundamento". La situación en que éste se halla ahora con respecto a la Ética, más bien en declive por muy diversos motivos, no permite sin embargo concluir que se trata de un pseudoproblema, muy al contrario: no es uno, sino múltiples problemas. Un único término traduce distintos planteamientos, todos ellos centrales, "fundamentales". Por todo ello, parece conveniente abogar por un uso más limitado y más exacto del término, acometer un recorte sustancial en las expectativas creadas en tomo suyo. Incluso puede ser recomendable el empleo de términos alternativos, como "razones» o "justificaciones", en beneficio al menos de una mayor claridad del lenguaje moral, ya de suyo bastante deteriorado, a decir de críticos influyentes.

Razones suficientes y otras estrategias constructivistas pueden también cumplir, y de modo mucho más flexible quizás, la función que venimos exigiendo al cquívoco "fundamento». La idea de un soporte incuestionable, otro lado accesible o de acceso directo a los forros de la existencia remite, como dice el texto literario, a los sombríos fundamentos, de modo que el saber diurno o racional tiene que adoptarlo con muchísimas reservas o bien adentrarse en las reglas de un saber sobre cosas sombrias, pero no puede realizar ambas operaciones a la vez sin pagar un precio elevado, muy elevado. El fundamento nos equivoca entonces, porque parece improbable que sean iguales o requiera de igual tratamiento la base del conocer y el forro o el suelo bajo el suelo. Los fragmentos de Heráclito prefiguraron cierto destino de la espcculación filosófica, forzada a decidir entre un sí y un no de perfiles gemelos: «el camino arriba y abajo es uno y el mismon. La intima semejanza de justicia-discordia, del día y la noche, ser-nada, bien-mal desvía al pensamiento por contradictorios caminos de paralelas que nunca se han de encontrar y no se convertirán en una sola cosa, como el fundamento del saber y el fondo de no saber. En tal situación la idea de ufundamenton requiere de un gran número de precisiones, a fin de que contribuya a la organización de los conocimientos logrados sobre la racionalidad práctica y no justamente a su demolición, en nombre de un punto de partida tan cierto como improbable. El motivo más fucrte para ir a un uso parsimonioso del término descansa precisamente en la voluntad previa de no arrancar la racionalidad en nombre de una razón más depurada y básica. De ahí a reclamar creencias que vengan a suplir ura ausencia de fundamento sólo media un paso, tan fatal para la razón y para los agentes razonables como lo es el dogmatismo de cualquier estirpe. Por lo tanto, el empleo bajo ciertas condiciones de un "fundamento» en Ética no sólo no puede sino que no debe renunciar a un grado importante de incertidumbre.

\section{El bien y sus razones}

Gracias a Hume el legado de distancias inabarcables entre contrarios se incrementó con la separación entre filosofía especulativa y práctica, entre razones y actos. Muy distintas nos parecen las razones alegadas para justificar un comportamiento y los motivos efectivos para la voluntad; la razón, algo inerte entre los empiristas, es incapaz de torcer lo que influye de modo incuestionable en la conducta. Después la Ética ha seguido condicionada en parte por aquella extrema lucidez y consiguiente condena de los artificios que hubieran podido tender lazos entre ambos polos, tanto en los libros como en el mundo. La opción reduccionista obliga a tomar una sola de entre las posibles soluciones $y$, dado el contexto de rechazo de la ra- 
zón, justifica la preferencia por una versión más pragmática. Al tratarse de acciones y no de problemas de pura teoría, sería preferible explicar con verosimilitud cómo se modifican en realidad las conductas, dejando para después el asunto de si ello es conforme a razón o no. Bien, he aqui un resultado que, al menos en una primera instancia, induce a mantener ciertas reservas sobre la bondad o la conveniencia de apurar planteamicntos teóricos sin ninguna medida, sobre todo cuando su traslación práctica invierte por completo el primitivo sesgo de la intención. Así se origina, por contradicciones insoslayables, el logico repudio a un pragmatismo que poco tiene de moral, pero tampoco carece de inconvenientes el exceso idealista, embarcado en una racionalidad menos práctica cada vez. La eficacia o sentido mismo de la Filosofía moral se pone, pues, a prueba en la tarea de cambiar de modo efectivo las actitudes, convencer, torcer o adherir voluntades; lo demás será descartado como un saber imposible e incomprensible. Sin embargo, la obviedad de tales conclusiones las hace parcialmente falsas, en tanto que mezclan de forma desconsiderada un problema analítico y un problema práctico. De una parte resulta en efecto conveniente que la Filosofía moral no se pierda por derroteros exclusivamente metaéticos, pero, de otro lado, una conceptualización muy rudimentaria la haría incapaz de articular en modo satisfactorio la expresión de los mismos asuntos prácticos sobre los cuales reflexiona. Por lo tanto, el abandono de términos tan rotundos como "verdad" o "fundamento» exige su sustitución por otros más adecuados, pero no desde luego por cualquier explicación procedente de cualquier convicción, sobre todo si ésta se encuentra muy poco elaborada.

Si tiene no sólo algún sentido sino mucho sentido todavia plantearse qué significa el fundamento para la Ética se debe precisamente a los dilemas en que se debate una nueva sensibilidad; ésta, poco acorde con puntos de vista enterizos, es todavía y con razón renuente a la pérdida de la racionalidad para la Filosofía práctica. De ahí que valga la pena renovar el enfoque de la Filosofía que se ocupó sin rodeos de la recepción de las teorfas, gracias a una atención pormenorizada hacia los efectos del lenguaje filosófico en los oyentes. Por consiguiente, "recepción» y sfundamentación" no deberían tratarse de modo in conexo. Tendría escasa justificación una actitud que mantuviese por principio un foso abierto entre razonamiento y persuasión, ruptura que no sólo es inadecuada para dar cuenta de ciertos fenómenos de la deliberación y la formación de principios morales, sino históricamente inaceptable a la luz de contribuciones teóricas y de las prácticas sociales que los compatibilizan durante períodos tan dilatados. Sin embargo hay hábitos que se elevan a principio; la doble verdad se instaló de tal manera en la conciencia moderna que aún hoy ignoramos cómo acortar la enorme distancia entre «es" y *debe», entre razón pura y razón práctica, entre la mayor virtud y la más crasa indigencia moral y práctica. De un lado nos interpelan las emociones, las pasiones, la vida misma, de otro, la teoría y sus férreas condiciones; pero olvidamos que no se trata de opciones intelectuales o no tan sólo intelectuales, sino de actividades. Por ello la investigación en pos del fundamento devuelva tal vez una imagen mezquina de la Etica, sobre todo cuando nada dice sobre lo que se pretende con tal seguridad fundamental, porque parece of vidar lo que es importante, las actividades. La Etica también refleja en sus planteamientos un mundo muy complejo y muy vivo de decisiones, imposicio- 
nes, etc., que no resisten la duda sobre su fundamento, pues no lo tienen ni pueden tenerlo. Es decir, con la fundamentación también pretende aislar y poner en evidencia un universo de actividades $\sin$ motivo o sin más motivo que la voluntad, alli donde el "deber» deja su sitio al "poder», la justificación moral a las decisiones sin legitimación. En consecuencia, los fundamentos no tienen cabida en la Ética sino como una forma de crítica, pues su construcción no cumple las reglas de una auténtica posición de elementos básicos.

Quienes dicen «todavía no» o "antes de", sean éstos un Habermas, Lorenzen, Kambartel, Schwemmer o un Tugendhat, explican cada uno a su modo y en el registro propio cómo acometer esa doble tarea de la Filosofia moral, sin gravosas o completas renuncias. Ir en pos de un fundamento suficiente significa aventurarse a contestar de alguna forma a solicitudes tan dispares, contestar, eso sí, con muchísimas cautelas, salvedades, clausulas, matices y mediaciones. Así pues, sabiendo el uso limitado que admite, el «fundamento" introduce una estrategia capaz de discriminar, de forma más o menos clara, qué conductas se consideran aceptables y qué otras merecen ser excluidas de la clase de «acciones morales». Al fin la formación de una teoría ética es subsidiaria de los objetivos que se esperan satísfacer con su ayuda. Si empleásemos términos algo enfáticos, podría sostenerse incluso que la fundamentación teórica aumenta la capacidad reflexiva sobre lo que está «bien» y lo que está "mal». El fundamento aportará un criterio aproximado de clasificación, pero no la sensibilidad o el gusto para distinguir acciones efectivamente buenas o malas, que eso es cuestión mucho más compleja y resultado de experiencias, cuya decantación ningún concepto filosófico o demostración racional puede abreviar. Cuenta E. Canetti en su autobiografía cómo empezó de forma casual una larga conversación con $\mathrm{H}$. Broch sobre la bondad de los seres humanos. ¿Conocian hombres buenos? Viena era entonces la ciudad de entreguerras y centro visible de una cultura en trance de extinción, con la estela inevitable de artistas apócrifos, preocupados por afirmarse en la fama y la estima ajena. "Yo" era la palabra más oída, todos hablaban de si mismos a fin de estar ciertos de su singular valía, pero cexistía entre la multitud de creadores y simuladores algún hombre verdaderamente bueno? La conversación entre los dos escritores se prolongó más de lo esperado, pues los improvisados jueces se sentían invadidos por la incómoda sensación de ir tasando con usura las cualidades de conocidos y desconocidos, desde una altura moral superior que no les correspondía en realidad. Buscaron, pues, ejemplos concretos, nombres de personas que se aproximasen al ideal de bondad, que no habían visto aún encarnado en alguno de los conocidos o desconocidos que frecuentaban las calles y los cafés vieneses. Por fin Broch pronunció un nombre: ¡El Dr. Sonnel Sonne, el hombre bueno, era persona muy independiente, sus virtudes principales parecian la lucidez y sabiduría. Poseía el don de lenguas y tan lejos llegaba su saber que, con inmenso dolor, llegó a pronosticar qué habría de suceder algún tiempo después. La rareza del Dr. Sonne estriba en su inteligencia y no deja de ser una curiosidad que su nombre real recuerde la metáfora platónica, el bien semejante al sol que todo lo ilumina. La Ética contemporánea lleva décadas aplicándose a explicar el mundo perdido de significados, tan raros ya como el Dr. Sonne. Quizás sea necesario revolver hasta sus «fundamentos» el panorama de la Filosofía moral, a fin de averiguar si tales diagnósticos pesimis- 
tas con respecto a un pasado de esplendor se justifican en algo más consistente que en la nostalgia y el rechazo de cualquier iniciativa tendente a ajustar condiciones poco favorables a una sensibilidad moral refinada, pulida por el tiempo; es decir, si cuenta con razones suficientes a su favor una voluntad de existir con arreglo a cierta dignidad, y acorde con la racionalidad más o menos evolucionada de la especie. El riesgo ha estado y está todavía en crear una Ética con cabeza desmesurada y pies ridiculamente pequeños 0 , dicho de otra forma, muy elaborada en el plano teórico y poco sensible a las cuestiones prácticas, a la existencia. Ahora bien, la circunstancia parece favorable a un desarrollo más equilibrado de ambos elementos, dado que no es fácil presuponer nada, que no hay que contar con certezas que en otros momentos se adecuaban al trabajo teórico o bien a la traducción práctica de los principios morales. Entonces la carencia de señales y de liderazgo, afortunada carencia ésta, pone en entredicho que, con tan anormal desarrollo, el filósofo sea infalible o pueda aquélla volver a pronunciarse sobre los problemas morales sin aportar algo más que unas convicciones, privadas de otra motivación más razonable que la misma fuerza de la creencia y del hábito de creer en ella. De manera que la incertidumbre que obligó a renunciar a fundamentos fuertes es o podría ser ahora la causa de una búsqueda de fundamentos pragmáticos o de razones suficientes para la deliberación y la acción. En este sentido sí cabe hablar de afundamento" y no parece haber otra posibilidad que ésta, la de afianzar los aspectos de razonabilidad y entendimiento, a fin de retomar las nociones de bien, justicia, virtud, felicidad y otras análogas. La búsqueda de la imagen de un ser humano virtuoso puede ser del todo errática e inçierta, sin una indicación razonable sobre el motivo y método de tal búsqueda, pues no sabriamos en realidad qué se busca. Así entra el "fundamento" en la Filosofía moral, por la puerta de sus indigencias, si bien en una versión distinta, más de argumentos y razonamientos plausibles que de suelo firme para uso de fundamentalistas o integristas. El forro de las cosas ya no es obvio, como parecía en otros momentos o contextos; tampoco lo es el "bien", por eso es necesario decir algo al respecto. El bien nada es sin el encarecimiento del bien. Las oportunidades de una Ética correctamente o completamente fundada son, pese a todo intento, más que dudosas, precisamente por eso hay que aprovecharlas.

La impaciencia ante lo dilatado de la tarea y lo incierto de sus resultados consurne, sin embargo, al filosofo y al no filósofo, que ven repetirse el ciclo: de las urgencias morales a los planteamientos metaéticos. La densidad de los razonamientos puede ser tanta que llegue a ocultar el motivo para y por que nacieron, que es la principal objeción que siempre se alega en contra de las teorías argumentativas, en su aplicación práctica; ese desánimo ante las posibilidades que ofrecen va más lejos, incluso afecta al sinsentido que, tanto el pragmático más simple como el nihilista más radical, achacan a la ocupación filosófica en su tesitura práctica. Y la crítica de tal sesgo se convierte en ataque en profumdidad, no sólo a una parte de los métodos filosóficos sino a la razón misma y la Filosofía en general. Aquel comprensible desánimo era un primer paso para el posterior descrédito del buen o mal hacer del filósofo moral. ¿Son los argumentos y las razones una nueva excusa para no llamar por su nombre a lo que está más cerca de nosotros? ¿Dónde y para qué guarda la lucidez quien dice oir bien las demandas y, sin embargo, enmudece porque se adentra en una 
búsqueda esotérica? En otro tiempo se habló de "compromiso", hoy se reclaman *soluciones" sin demora, al modo pragmático que nos es ya usual; en ambos terrenos pueden ser muy decepcionantes la actividad y actitud del filósofo contemporáneo. Por otra parte, la imagen que nos llega de sus artifices es más bien inestable, no sabemos si le conviene enumerar los males infinitos, recorrer el camino de las negaciones, o pronunciarse por bienes inexistentes, la diatriba o la defensa. Lo primero significa repetición cansina de lo ya conocido, lo segundo una fuga hacia las ideas o los ideales que forman un mundo ajeno al propio. La ausencia de referencias concretas nos incomoda por otra parte, pues sólo dice, muy a su pesar, cuán lejos estamos de la estación benévola en donde ha de imperar la moralidad.

Por todo ello, la expresión "en fundamento» apenas se emplea, o quizás sería mejor decir que no se emplea en el mismo sentido que le daban autores de otra época; por ese motivo suena a cierto arcaísmo, por eso mismo el «antes de», "todavia no» o cualquier otra fórmula semejante vale para decir que debemos indagar aún sobre el asunto, con las limitaciones ya expresadas. Es decir, no puede esperarse demasiado de lo que el "fundamento haya de aportar a la construcción de la Filosofía moral, lo cual no es obstáculo para seguir considerándolo como el test definitivo, la cuestión más reveladora sobre el estado del lenguaje moral y sobre el estado de opinión existentc con respecto a la bondad o maldad y sus requisitos respectivos. No es posible por tanto una última fundamentación de la Ética, pero los fundamentos, justificaciones o razones de los actos no sólo son posibles, sino que son imprescindibles. "Razones suficientes* para la acción moral, para el juicio argumentado y la decisión justificada, aunque no un fundamento abso- luto de la Élica. Parece ser un inequívoco signo de prudencia el solicitar que haya al menos una razón suficiente tras toda decisión, sobre todo si ésta acarrea serias consecuencias, tanto si éstas afectan a un número reducido de seres como si se trata de una declaración de guerra de todos contra todos. La objeción de que las razones apenas suficientes se empequeñecen aún más ante situaciones de gravedad y magnitud evidentes no es un argumento, pues precisamente el probado riesgo de que dejemos atrás las razones representa un motivo más para negarse a poner bajo el mismo criterio y medida a razón y sinrazón. El fundamento como base de justificaciones ulteriores alcanza así el único sentido posible, es decir", dentro de un continuum de situaciones, intenciones $y$ actos determinados. Indica la existencia de un problema y el procedimiento para plantearlo del modo más correcto, es decir, atañe a la necesidad de hacer explícitos los supuestos, gracias a los cuales se toman decisiones o se argumenta sobre asuntos prácticos. La fundamentación práctica pretende apartar el decisionismo, para estar udentro" o y no ufuera" de los argumentos, a pesar de los consabidos riesgos de circularidad, dogmatismo, el regreso al infinito, etc. Ahora bien, también pudiera suceder que la dificultad que comporta la puesta en marcha de un procedimiento argumentativo, unida a la inestabilidad del mismo, es decir, a la evidencia de que el modelo debe ajustarse a la circunstancia en cuestión, a los agentes, el caso y demás elementos adicionales, en suma todo lo que entra a formar parte de la relevancia del razonamiento, pudiera incitar a una operación más rápida, en la cual el fundamento claro y distinto viene a paliar la comprensible angustia y desconcierto que acompaña a la reflexión práctica. La simplicidad puede también ser un 
argumento, incluso más aceptable que la complejidad bajo ciertos respectos, pero las consecuencias de tal preferencia han de ser ponderadas y, quizás, también valoradas negativamente.

\section{Razones suficientes}

La argumentación moral no es muy distinta de otros tipos de razonamiento. sigue el procedimiento habitual de deducir consecuencias a partir de premisas. Un caso particular remite a una regla general, bajo la que éste se subsume; ahora bien, cuando hablamos del silogismo práctico, los casos y las reglas se refieren a asuntos de indole moral, es decir, una variedad especialmente problemática, lo cual hace suponer que su justificación pragmática y la justificación general, de tipo teórico, no serán exactamente iguales. La conexión interna entre las acciones, no siempre evidente ni siquiera apelando a la intencionalidad, así como las muy variadas modalidades de interdependencia que pueden darse entre los agentes que las producen, introducen una variable que modifica el mecanismo mediante el cual formamos opiniones y formulamos alguna conclusión sobre hechos o casos prácticos, de manera que habrá de rechazarse la deducción como único procedimiento a emplear aqui. Los principios que mueven a argumentar no son tan indudables, por eso precisamente se disputa y se razona al respecto, no en razón de lo contrario. La fundamentación pragmática resulta de añadir al concepto de «fundamentación deductiva* el contexto de exigencias entre personas y grupos. Parece lógico suponer que no da lugar al dogmatismo, pues las normas asî fundadas valen en la medida en que son relevantes para dar satisfacción a las necesidades de quienes llegaron a darles forma. Los argumentos operan desde y sobre la acción mis- ma, por eso la circularidad afectará a una fundamentación teórica, pero la fundamentación pragmática la elude, ya que ni es "última» ni pone el principio antes de proyectar la acción. Claro es que no ofrece standards de fundamentación, pero tiene por ventaja la ausencia de vicios de circularidad, porque sólo representa una parte de la «fundamentación»: las condiciones imponen qué se fundamenta "materialmente".

Por tanto, la fundamentabilidad teórica resulta imposible en términos absolutos, pero si suponemos agentes competentes y consecuentes, tendremos una red de razonamientos y justificaciones. Tendremos una construcción en lugar de un Faktum de la razón práctica. Gracias a esta imposibilidad, la Ética está en condiciones de iniciar el regreso hacia la Moral, hacia lo que los sujetos consideran como moralmente relevante. El doble orden de las normas y el de su contexto de aplicación conduce asimismo a una doble tarea. La Filosofía moral se ocupa tanto de cxplicar la estructura y condiciones que hacen de la Ética una disciplina y un discurso racional, como de comprender el "qué» de ésta, los problemas morales. Los imperativos teóricos y prácticos cristalizan tanto en una tradición como en un tiempo propio del hacer y el decir, en el cual el filósofo moral efectivamente ha de moverse como "guarda e intérprete", pero también como agente que delibera y se decide sin subterfugios. En una duplicidad de perspectivas a compatibilizar, la mediación vuelve a emerger como lo principal, como la prueba de que el proceso previo de razonar, fundamentar, deliberar, etc., fue correctamente planteado. En la incertidumbre, bienvenida sea una metodología que ponga al descubierto los resortes del explicar y comprender, pero que también muestre con crudeza la imposibilidad de dar por concluido el asunto, pues la justifica- 